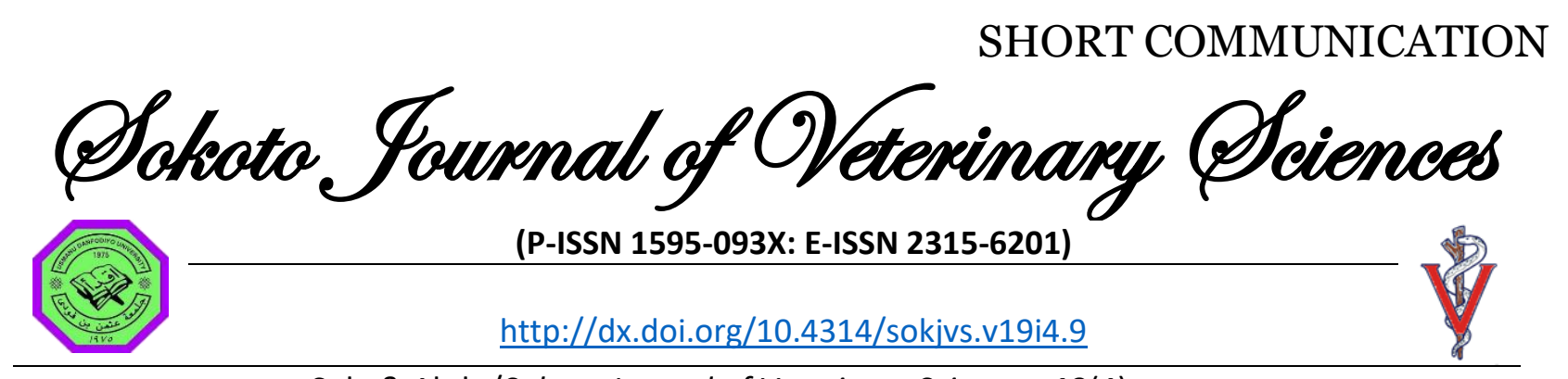

Sule \& Abdu/Sokoto Journal of Veterinary Sciences, 19(4): 210 - 213.

\title{
A retrospective study on monthly disease reports from some area veterinary offices in Bauchi State, Nigeria
}

\author{
AG Sule ${ }^{1 *} \&$ PA Abdu ${ }^{2}$ \\ 1. Department of Veterinary Public Health and Preventive Medicine, PMB 1069, University of Maiduguri, \\ Nigeria \\ 2. Department of Veterinary Medicine, Ahmadu Bello University, Zaria, Nigeria
}

*Correspondence: Tel.: +2348029805011; E-mail: suleadamu@yahoo.com

\begin{abstract}
A retrospective study to determine the completeness and content of monthly disease reports (MDRs) from eight Area Veterinary Offices (AVOs) was conducted at the office of the Director Veterinary Services (DVS) Bauchi State, Nigeria. The result revealed submissions of MDRs made by all the AVOs at the office of the Director Veterinary Services were less than the expected 60 monthly disease reports. Among all the AVOs, Azare had the highest available report that reached $70 \%$ of the expected reports, while Shira presented the lowest available MDR of $10 \%$. An observation on the content of MDR showed no uniformity in the format of disease reporting from all the AVOs. The content also showed a total of 1,251,886 cases which were broadly categorized into poultry $(225,891)$ cases and $1,025,995$ other livestock cases. There was a significant association in the reporting of livestock cases when compared to poultry cases ( $p<0001$, Chi-square $=138600$ ) in all the AVOs. The result showed incompleteness in the availability of MDRs presented by AVOs in the office of DVS which is suggestive of underreporting. The results from this study tend to highlight the need to strengthen monthly disease reporting among AVOs in Bauchi State, Nigeria to enable the office of the Director of Veterinary Services to use the report for early prevention and control of prevailing animal diseases and notification of diseases at national and international level.
\end{abstract}

Publication History: Received: 01-04-2021

Revised: 25-07-2021

Accepted: 28-07-2021

Keywords: Bauchi State, Content and Completeness, Monthly disease report, Nigeria, Retrospective study

\section{Introduction}

Monthly disease reports are records of diagnoses and treatments of sick and abnormal animals presented by farmers to veterinary staff and those diseases encountered by veterinary staff at the abattoir that are transmitted along the disease reporting hierarchy. Though, considered a passive form of surveillance, a monthly disease report is useful for early detection of a disease outbreak; for planning and monitoring of disease outbreak; for providing sound advice to livestock farmers; for the performance of international disease reporting obligations; for declaration of freedom from diseases especially for diseases with clear clinical signs; for quantification of the amount of the disease in a given 
population (prevalence) and for discontinuation of a control programme like vaccination following the eradication of a particular disease as was the case with Rinderpest (Roeder et al., 2013). Although Animal disease reports were among the mandatory duties of States in Nigeria, a review on animal disease reports had shown some inefficiency in disease reporting especially, with regards to under-reporting, completeness and timeliness in disease reports and especially poultry diseases (Ogundipe et al., 1989; Gashash, 2009). The availability of animal disease reports is critical for effective prevention and control of animal diseases at state and national levels. This study was therefore aimed at examining the availability and the content of animal disease reports as well as explore the possibility of a bias in reporting livestock disease at the office of the Director Veterinary Services, Bauchi State, Nigeria.

\section{Materials and Methods}

\section{Study area}

This study was carried out within the office of the Director Veterinary Services, Bauchi state, Nigeria which occupies a landmass of $48,382 \mathrm{sq} \mathrm{km}$ that is located within $7^{\circ} 52^{\prime} \mathrm{N}$ and $8^{\circ} 56^{\prime} \mathrm{N}$ and longitudes $7^{\circ}$ $25^{\prime} \mathrm{E}$ and $9^{\circ} 37$ (Independent National Electoral Commission (INEC), 2008). The State shares boundary with Jigawa and Kano on the Northwest, Kaduna on the West, Plateau, Taraba Gombe States on the South and Yobe State on the East. There are twenty Local Government Areas (LGA) in the State, a human population of $5,515,300$ (INEC, 2008) that belong to many ethnic groups whose occupation is mainly farming. The population of animals in the State as at 2020 were 580,199 cattle, 254,515 sheep, 439,911 goats and $6,006,264$ poultry population (NAERLS \& FMARD, 2020).

\section{Methods}

Records of monthly animal disease reports available for the period June 2010-May 2015 from eight AVOs (Azare, Dambam, Darazo, Dass, Gamawa, Ganjuwa, Shira, and Toro) in Bauchi State were manually observed for completeness and uniformity. Completeness means 60 months of the report were available. And this gives a percentage of $100 \%$. All the cases presented were counted to find the total number of cases during the 60 months and the total number of cases presented by each AVO. Cases of livestock and poultry in each AVO were counted separately. A total number of livestock cases was compared to the total number of cases presented from each AVO to see if there is any statistical association between the two variables.

\section{Data analysis}

A chart was used to reduce and present available disease reports at the office of the Director of veterinary services, Bauchi State. Counts were used for counting the total number of cases presented by each AVO and the cases that were either livestock or poultry. To test the strength of association between total reported cases and reported livestock cases $\mathrm{Chi}$ squared statistic was used to see if there is a bias in reporting livestock cases presented in reports by all the AVOs. P-value $<0.05$ was considered statistically significant.

\section{Results and Discussion}

The availability of MDRs at the office of DVS seems to imply that all the AVOs were performing their disease reporting obligation. The finding that less than $70 \%$ of the reports presented during the 60 month reporting period were available at the office of the DVS for all the AVOs (Figure 1) seems to indicate that animal

Table 1: Distribution of cases of monthly disease reports available at the office of the Director Veterinary Services Bauchi State, Nigeria

\begin{tabular}{llll}
\hline Area office & $\begin{array}{l}\text { Total livestock and poultry } \\
\text { cases }\end{array}$ & Livestock cases & $\begin{array}{l}\text { The proportion of livestock cases in monthly } \\
\text { disease reports (\%) }\end{array}$ \\
\hline Azare & 179286 & 125337 & 69.9 \\
Dambam & 141744 & 130229 & 91.9 \\
Dass & 112370 & 109965 & 97.9 \\
Darazo & 126497 & 99125 & 78.4 \\
Gamawa & 200413 & 179435 & 89.5 \\
Ganjuwa & 153739 & 153728 & 99.9 \\
Shira & 34590 & 26520 & 76.7 \\
Toro & 303247 & 201656 & 66.5 \\
Total cases & 1251886 & 1025995 & 81.9 \\
\hline
\end{tabular}

$P$ value $=<0.0001$, Chi square $=138600$ 


diseases were
underreported.
Underreporting of
diseases have the
potential to yield
inaccurate information
that could negatively
affect the computation
of the amount
(prevalence and
incidence) of animal
diseases in the State; and
decisions on planning,
funding, budgeting and
prioritization of diseases
that need to be
controlled to avert losses
that could be associated
with a disease outbreak.
Underreporting of
animal disease found in

this study agrees with the findings of Gashash (2009) in some states in Nigeria and Tsofo (2012) in Borno State. These findings continually point to the need for better ways to improve disease reporting. Other contributory factors to low disease reporting especially of poultry cases could include the inability of village poultry farmers who mostly owned these chickens in Bauchi State to afford the cost of treating sick chicken and their preferences for consumption of sick chickens (Sule, 2017).

Even though a total of $1,251,886$ cases $(225,891$ poultry and 1,025,995 livestock) were registered from all AVOs during the study period, disease reporting appears to be strongly associated with livestock cases in all AVOs ( $p<0.0001)$. This tends to imply that AVOs were reporting fewer poultry cases even though poultry has the largest population of animals in Bauchi State. Such findings may be attributed to low commercial poultry activity and low impact of veterinary services among village poultry (Adene \& Oguntade, 2006).

The observation that all the AVOs use different formats to send monthly disease reports could make it tedious to summarize the report and use it effectively for decision making. This emphasizes the importance of adopting a standardized disease reporting format, such as using a customized disease reporting form or adopting the AU-IBAR disease reporting template which could enable users to send reports via electronic devices such as cell phones and computers.
The study recommends that the Bauchi State Department of Veterinary Services should enhance disease reporting among its staff through employing/deploying more staff to a unit that will discharge the duties of designing a format for disease reporting and also for collecting and compiling disease reports presented by AVOs. The State should re-train existing staff on how to report disease from their AVO using a particular format of disease reporting. The State should introduce the use of electronic means of disease reporting to an appointed computer literate desk officer who will receive the MDRs report via computers and cell phones. The State should provide incentives to staff that consistently have their reports available at the office of the Director of Veterinary Services and also punish those who do not provide their reports on time.

\section{Conflict of Interest}

The authors declare that there is no conflict of interest.

\section{References}

Adene DF \& Oguntade AE (2006). Structure and Importance of the Commercial and Village Based Poultry Industry in Nigeria, FAO, Rome, Italy. Pp 1-109.

Gashash IA (2009). Annual Assessment of Disease Reporting Performance of States. Epidemiology Unit, Federal Department of Livestock, Nigeria. 
Independent National Electoral Commission (INEC) (2008). Bauchi State. In: Nigeria Atlas of Electoral Constituencies. Independent National Electoral Commission, Garki, Abuja, Nigeria. Pp 42-50.

NAERLS \& FMARD (2020). Wet Season Agricultural Performance in Nigeria. NAERLS Press, Zaria, Pp 152.

Ogundipe GAT, Oluokun SB \& Esuruoso GO (1989). The Development and Efficiency of the Animal Health Information System in Nigeria. Preventive Veterinary Medicine. 19; 7(2): 121-135

Sule AG (2017). Epidemiology of Newcastle Disease in Village Chickens in Bauchi State, Nigeria.
PhD. Thesis, Department of Veterinary Public Health and Preventive Medicine, Faculty of Veterinary Medicine, Ahmadu Bello University Zaria, Nigeria. Pp 1-126.

Tsofo Al (2012). Factors Influencing Disease Reporting in Borno and Gombe State, North-Eastern, Nigeria M.Sc Thesis. Department of Community Medicine, Faculty of Medicine, Ahmadu Bello University Zaria, Nigeria. Pp 168.

Roeder P, Mariner J \& Kock R (2013). Rinderpest: The veterinary perspectives on eradication. Philosophical Transaction of the Royal Society London B Biological Sciences, doi.10.1098/rsbp.2012.0139. 